\title{
BIM Applications in the World
}

\author{
Bizhou $\mathrm{Li}^{1, \mathrm{a}^{*}}$, Jian Yang ${ }^{2, b}$ \\ ${ }^{1}$ Faculty of Architecture and City Planning, Kunming University of Science and Technology, \\ Kunming, Yunnan, China \\ ${ }^{2}$ Faculty of Architecture and City Planning, Kunming University of Science and Technology, \\ Kunming, Yunnan, China \\ abiz.0804@gmail.com, bsnoobygg@126.com
}

Keywords: BIM, information, modelling, applications

Abstract. Building Information Modelling (BIM) is a powerful tool for architecture, engineering and construction industry. Nowadays, it is widely used in the world. This paper first introduced the development of the design tools, generally three stages, from pen and paper to 3D design with information. Then illustrates the BIM application situations in different countries in the world. At last draw a conclusion that the development of BIM in the world is optimistic.

\section{Introduction}

BIM is short for Building Information Modelling, which is a prominent progress in architecture, engineering and construction industries. When using BIM technology, a digital model will be built accompanied with this process. After the model finished, a precise digital model will be used to provide nearly all information which is need by the project, such as accurate geometry and other data which needed to help the building process.

Architecture, engineering and construction (AEC) design can be divided into three stages. The first stage is the traditional methods, which use the basic tools like paper, pen and ruler to implement design work. This stage origin from the ancient time which is a very traditional way to do all kinds of design. This method is effective and was the only one way for the designers to do design in the past. It take a lot of time and hard to modify if there are some changes in the design.

The second stage of AEC design method is 2D CAD design. After the computer was invented, design without pen and paper is coming true. When the Second World War finished, there some military technologies expand to the civil field. One crucial technology is Sketchpad, which first developed by Ivan Sutherland, was the origin of CAD technology. As the computer initial being invented, as the equipment was heavy and expensive, also due to the slow operation speed, the technology of CAD was not as popular as it should be. After several years, when the personal computer was invented, the equipment becoming lighter and cheaper, which conduct the spread of CAD technology. Gradually, it becoming the design method nearly all the AEC designers using it. Till now, it is also one of the most popular design tools.

The next stage is changing the $2 \mathrm{D}$ CAD to $3 \mathrm{D}$ modelling. This is a big change that can lead a drastic update such as the emerging of BIM technology. BIM has many benefits that $2 \mathrm{D}$ drawing cannot catch up. The BIM design process can be more integrated that lead to better building qualities and decrease the money spent on projects. At the same time reduced project duration. Also, BIM can help the procedure of building maintenance by providing necessary information and possibilities.

As BIM have so many advantages, numbers of countries' governments raising some policies to promote their development of BIM application. Some countries in north Europe, such as Finland Sweden becoming the eminent countries which using BIM technology. In the other part of the world, such as US, UK, Singapore, Hong Kong and South Korea, are implementing BIM in different levels. It must say that BIM have becoming a worldwide trend in terms of architectural design, engineering and construction. 


\section{BIM in Nordic Countries}

Finland. Finland adopted BIM technology earlier than any other countries in the world. Finland has an advanced technology development level. In Finland, the scale of the construction industry is small and agile, the trust system has a long history, and standards system are open, which shows perfect environment for BIM application [1].

Norway. Similar to Finland, Norway also has a small construction industry. The government of Norway is the main regulatory bodies which is effective. All these elements actively promoting BIM implementation in Norway as a successful story. Now the BIM becoming essential for all major infrastructure and government building projects.

Sweden. Sweden is also a Northern Europe country. It is catching up the pace of Finland and Norway in BIM implementation. Now, Sweden reach the leading status of using BIM to design and build large complex infrastructure projects. It was a big event that in 2009 the OpenBIM organization was established and making BIM standards in Sweden.

\section{BIM in the UK}

UK is one of the prominent countries in terms of implementing BIM technology. In 2011, the NBS (National Building Specification), which is owned by the Royal Institute of British Architects (RIBA), released the first Building Information Modelling (BIM) Report. Then it became a series of yearly reports. Till now (2015) there are 5 reports released. Also, in UK, the government said that in 2016, they will implement Level 2 BIM for all the publicly funded projects [2]. Now, as the target time was near, "the industry broadly supports the Government's approach, describing it as being on 'the right track", [3]. Date back to 2010, when NBS first mentioned they will conduct the use of BIM, it is still used by very few design communities, which is less than $15 \%$. Nevertheless, it draws many attentions to this new technology. Many design companies started to aware of BIM and set up some schedules to make a transition to design by BIM. So this report have the function of promote design companies to update their design technology.

In the investigation of BIM awareness and usage in UK, we can clearly see that the trend of the proportion of professionals who aware of BIM is increasing, from total 58\% in 2010 to $96 \%$ in 2014. The trend of proportions of professionals who currently using BIM is similar, from 13\% in 2010 to $54 \%$ in 2013 , however, in 2014 , there was a slight decrease to $48 \%$ who currently using BIM. As the report says [3], there are three reasons that cause this decrease. First reason is that after recession period, the workloads increase, so time to invest in the software decreases. Second reason is according to the Innovation Adoption Lifecycle curve, the adoption will slows for a while as the "Late Majority" join, which lead to the slow down. The third reason is the survey population have some changes. In all, the slight decrease dose not means they reached BIM's peak. The adoption of BIM will increase after this period of time.

\section{BIM in the US}

In the United States, the National Institute of Building Sciences (NIBS) released the National BIM Standard-United States (NBIMS). Although NIBS is an organization which was approved by the Congress, the fund is not directly from the government. The goal of that organization is to establish the standards to operate information effectively so that they can create better facilities. Now there are two versions of NBIMS, the third version of NBIMS will release in mid-2015.

In 2012, there is a research conducted by McGraw-Hill Construction shows that the using of Building Information Modelling dramatic increased from 2007 to 2012. The statistic shows the percentage of relevant companies in the US using BIM jumped from 17\% in 2007 to $71 \%$ in 2012 [4]. 


\section{BIM in Australia and New Zealand}

The building information modelling usage is becoming wider including the country of Australia and New Zealand. In these countries, increasing number of architects, engineers, contractors now using BIM technology. Now in Australia and New Zealand, even new to the use of BIM, realized the value of BIM implementation and they will invest more money in BIM development. There are more than 51\% of their relevant companies using BIM on more than $30 \%$ of the projects using BIM. The report shows that in the end of $2015,74 \%$ of companies will use BIM in over $30 \%$ of their projects. There are also some companies do not use BIM technology. Research indicates 54\% of non-users working just in Australia and New Zealand, which is a larger amount compared with $38 \%$ of those working in and out of Australia and New Zealand [5]. Some of the non-users believe that BIM does not an efficient tool for smaller projects. Also, the demands of owners, including the government, are key part for the companies to develop themselves using BIM. Some companies do not use BIM especially which just working only on in-country projects think that their competitors and clients do not use BIM whereas their peers which working in global companies do not think so. So, more international the company is, more BIM technology they will use.

\section{BIM in Singapore}

In Singapore, the agency which serve for the country's construction industry is Building and Construction Authority (BCA). Long before the concept of BIM was introduced, the Singapore Government noticed the importance of Building Information Modelling. As early as 1982, the BCA came up an idea of Artificial Intelligence plan checking. Then from 2000 to 2004, they developed the project of Construction and Real Estate NETwork (CORENET). This project is used for the examination and approval projects on line [6].

In 2011, BCA released the BCA's Building Information Modelling Roadmap. It indicates that "BCA targets the construction industry to use Building Information Modelling (BIM) widely by 2015".

In order to make some needs for BIM application, the Singapore Government decided to use BIM technology in all government projects. The aim is that all the projects larger than $5000 \mathrm{~m}^{2}$ should submit final BIM model.

Also, the Singapore Government persuade universities to set up courses of BIM, which can train students both full-time and part-time so that more people will get trained by the professional training institution.

\section{BIM in Hong Kong}

In Hong Kong, some government departments have used Building Information Modelling. For instance, the Hong Kong Housing Authority (HA) has implementing BIM from 2006. Since then, the Housing Authority using BIM technology to develop more than 19 projects of public rental housing projects. The BIM implementation of these projects are developed in different stages, range from feasibility to construction. The professionals and technical staff in HA have essential skills and experience to handle BIM problems in the process of implementation.

In 2009, the Hong Kong Institute of Building Information Modelling was established. The purpose of this organization is to "uphold and advance the standard of competence for the profession and to promote the interests and recognition of its members within the industry and community".

\section{BIM in South Korea}

In the year of 2008, in South Korea, the first BIM conference was held by buildingSMART Korea. Since then, two organizations have been found. They are the Korea Construction IT Convergence Institute and the Korea Institute of Building Information Modelling. Also, some online BIM communities was found since that time. 
Now, South Korea's BIM application has been conducted for years. According to the statistics, "nearly $60 \%$ of relevant industry companies now using BIM, 39\% of them know about BIM but do not use it, only 3\% saying they have not heard about BIM" [7]. It shows that the usage rate of BIM is high, at least there are more BIM users than non-BIM users. However, the current level of BIM usage in South Korea still lower than the North America statistics in 2012, which is $71 \%$ which adopt BIM. Nevertheless, the growth speed of BIM usage is fast. In the near future the adoption of BIM in South Korea will jump to a higher level.

Also, there are some cases successfully conducted by using BIM, such as Dongdaemun Design Park and Plaza Project, NCSoft R\&D Centre, The Theme Pavilion of Expo 2012 Yeosu and the New Korea Power Exchange Headquarters Building. They are all successful cases that were well operated by using BIM.

\section{BIM in China}

China is one of the fastest growing BIM using country. Now, China is conducting huge projects widely and more and more projects using BIM, which can optimize design and at the same time enhance the productivity. In 2015, the Dodge Data \& Analytics released a report which shows in China the proportion of high level BIM usage members will doubled in the future two years. Also, the companies which using BIM making a big profit from the reducing of the cost of time. The non-users attitude in China is amazing, $89 \%$ of non BIM users have positive attitudes, no one says they have used BIM technology and will not use anymore in the future [8]. Therefore the usage and adoption of BIM will continually grow.

In China, there are many cases using BIM to conduct the whole process of the project. The one called Phoenix Media Centre in Beijing was built by using the technology of BIM in the whole process, from design to construction. The shape of this building was dynamic which like a big balloon. It is contains media production spaces and office spaces. By using BIM, the team of this project reduced some risks they will meet and come up with a better solution of it.

Another case in China is the Shanghai Tower, which is a 121-story skyscraper, now is under construction. BIM played a crucial role of in stages of this building, from design to construction, due to the sophisticated shape and function. Successful BIM application is the key element of this project doing so well.

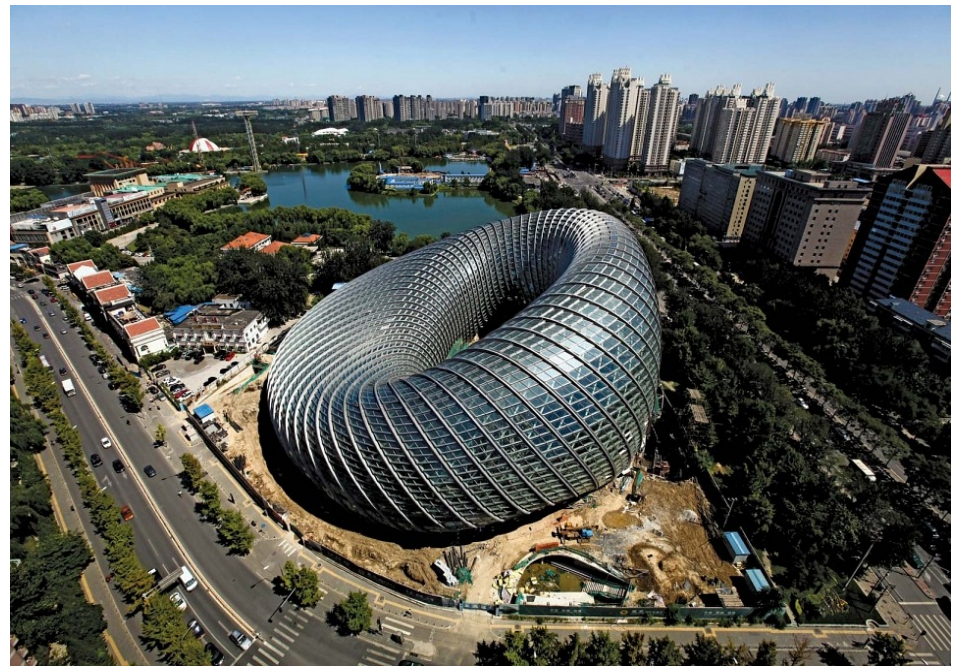

Figure 1 Phoenix International Media Centre, Beijing. Source:http://static.thousandwonders.net/Phoenix.Internatio nal.M edia.Center.640.2196.jpg

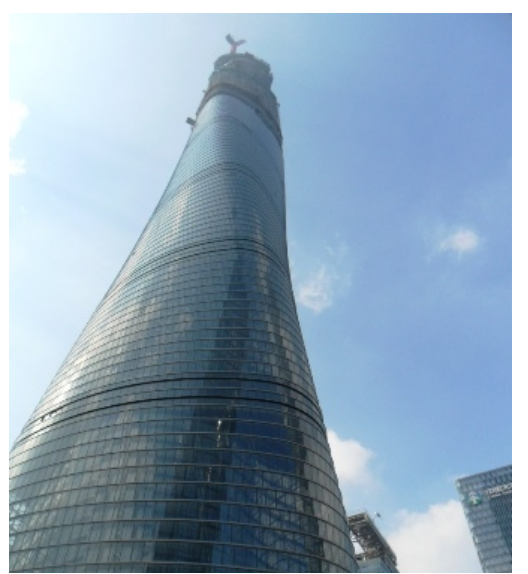

Figure 2 Shanghai Tower. Source:http://blogs.angloinfo.com/f eel-high-in-shanghai/files/2013/10/ Shanghai-Tower2.jpg 


\section{Conclusion}

Through the research of BIM applications in different countries in the world, such as Nordic Countries, US, UK, Singapore, Australia, New Zealand, South Korea and China, we can find the trend of BIM application in the world is optimistic. Most of relevant companies know the technology of BIM, some of them have already used BIM in their work, large proportion of companies have plans to use BIM in the future several years. There is a common view that BIM represent the future technology trend.

In some countries, governments also play important roles of conduction BIM applications. Some countries have their plans of using BIM technology so that they can keep up the pace of the world trend. The involvement of government is good for the architecture, engineering and construction industries to promote them to use new technologies.

\section{References}

[1] Information on https://www.buildingsmart.fi/

[2] Information on https://www.gov.uk/government/

[3] NBS National BIM Report 2015, RIBA Enterprises Ltd., 2015

[4] The Business Value of BIM in North America: Multi-year Trend Analysis and User Ratings (2007-2012), McGraw-Hill Construction, 2012

[5] The Business Value of BIM in Australia and New Zealand: How Building Information Modeling is Transforming the Design and Construction Industry, McGraw-Hill Construction, 2014

[6] Singapore BIM Guide, Building and Construction Authority, 2013

[7] The Business Value of BIM in South Korea: How Building Information Modeling is Driving Positive Change in the South Korean Construction Industry, McGraw-Hill Construction, 2012

[8] The Business Value of BIM in China, Dodge Data \& Analytics, 2015 